\title{
EFEITOS DA TEMPERATURA NA GERMINAÇÃO DE SEMENTES E NA FORMAÇÃO DE PLÂNTULAS DE Cedrela fissilis
}

\author{
Ademir Kleber Morbeck Oliveira ${ }^{1}$, Luciene Andrade Barbosa ${ }^{2}$ \\ ${ }^{1}$ Biólogo, Dr., Programa de Pós-Graduação em Meio Ambiente e Desenvolvimento Regional, Universidade Anhanguera-Uniderp, \\ Campo Grande, MS, Brasil - akmorbeckoliveira@gmail.com \\ ${ }^{2}$ Bióloga, Acadêmica do Programa de Pós-Graduação em Meio Ambiente e Desenvolvimento Regional, Universidade Anhanguera- \\ Uniderp, Campo Grande, MS, Brasil - luciene.ab@gmail.com \\ Recebido para publicação: 03/09/2013 - Aceito para publicação: 31/01/2014
}

\begin{abstract}
Resumo
O cedro-rosa é uma espécie que ocorre em diversas formações florestais brasileiras, incluindo o Pantanal. As espécies dessa família possuem importante papel na medicina tradicional, além de sua utilização como madeira, empregada em compensados. O presente trabalho tem como objetivo avaliar os efeitos de diferentes temperaturas sobre a germinação e formação de plântulas de cedro-rosa, com frutos coletados no Pantanal do Negro, Mato Grosso do Sul, Brasil. Foi determinado o teor de água e avaliaram-se os efeitos das temperaturas constantes de $20,25,30$ e $35^{\circ} \mathrm{C}$ e alternadas de $20-30$ e 25 $35^{\circ} \mathrm{C}$, sob fotoperíodo de doze horas de luz branca, com delineamento experimental inteiramente casualizado. O grau de umidade nas sementes foi de 50,5\%, com as temperaturas constantes de 20 e $25^{\circ} \mathrm{C}$ e alternada de $20-30{ }^{\circ} \mathrm{C}$ apresentando os maiores valores médios de germinação, 91,85 e $87 \%$, respectivamente. $\mathrm{O}$ índice de velocidade de germinação foi maior nas temperaturas de 25 e $30{ }^{\circ} \mathrm{C}(8,2)$, com melhor tempo médio de germinação na temperatura de $30^{\circ} \mathrm{C}$ (5,8 dias). A temperatura constante de $25^{\circ} \mathrm{C}$ apresentou a melhor média de crescimento e produção de matéria seca e foi a mais adequada. Palavras-chave: Pantanal; sementes florestais; plântulas; Meliaceae; cedro-rosa.
\end{abstract}

\begin{abstract}
Effect of temperature on seed germination and seedling formation of Cedrela fissilis. The Cedrela fissilis Vell is a wide dispersion species that occurs in several Brazilian forest formations, even in Pantanal. The species of this family have an important role in natural medicine and its wood is used to plywood. This work aims to evaluate the germination and seedling production of Cedrela fissilis Vell under different temperatures. We used fruits collected from Pantanal of Negro, Mato Grosso do Sul, Brazil. It was quantified the water content and evaluated the effects of constant 20,25 and $30^{\circ} \mathrm{C}$ and alternated $20-30$ and $25-35^{\circ} \mathrm{C}$ temperature, twelve photoperiod under white light. For statistical analysis, the experimental design was completely randomized design. The seed moisture content was $50.5 \%$ and constant temperature of 20 and $25{ }^{\circ} \mathrm{C}$ and alternated, $20-30{ }^{\circ} \mathrm{C}$, the best treatments for germination, 91,85 and $87 \%$, respectively. The germination speed was higher at temperatures of 25 and $30{ }^{\circ} \mathrm{C}$ (8.2), with the best time of germination at $30^{\circ} \mathrm{C}$ (5.8 days). The constant temperature of $25^{\circ} \mathrm{C}$ had been the best for the production of dry matter and growth. Taking into account all parameters, the temperature of $25^{\circ} \mathrm{C}$ was the most suitable.

Keywords: Pantanal; forest seeds; seedlings; Meliaceae; Cedro-rosa.
\end{abstract}

\section{INTRODUÇÃO}

Estudos sobre germinação de sementes de espécies do Pantanal, em condições laboratoriais, são poucos, encontram-se dispersos e escassos e muitas vezes não apresentam informações aprofundadas, devido à ausência de padronização de procedimento e às variações de comportamento e disponibilidade das sementes (SALOMÃO et al., 2003).

Entre as espécies nativas dessa região está o cedro-rosa (Cedrela fissilis Vell.), família Meliaceae, podendo ser encontrado do Rio Grande do Sul até Minas Gerais, principalmente nas florestas semidecídua e pluvial atlântica (LORENZI, 2008). 
Trata-se de uma espécie que se comporta como secundária inicial ou tardia, encontrada tanto na floresta primária, principalmente nas bordas da mata ou clareiras, como na floresta secundária, tendo sua importância econômica relacionada à madeira, empregada em compensados, móveis em geral, na construção civil, naval e aeronáutica, além de ser largamente empregada em paisagismo e na composição de reflorestamento heterogêneos de áreas degradadas (LORENZI, 2008).

Entre as madeiras leves, o cedro é a que possibilita o uso mais diversificado, superado somente pela madeira da espécie Araucaria angustifolia (Bertoloni) (pinheiro-do-paraná). Sua madeira é semelhante à do mogno (Swietenia macrophylla King), sendo, porém, mais mole e de textura mais grossa (CARVALHO, 1994).

Muitos gêneros dessa família produzem vários compostos com ação inseticida e medicinal, apresentando propriedades terapêuticas, como febrífuga, adstringente e vermífuga, entre outras (LORENZI, 2002). De acordo com Xavier et al. (2003), sua exploração é realizada de maneira extrativista, havendo carência de informações sobre processos que viabilizem o seu plantio em programas de reconstituição ou para fins comerciais.

A germinação pode ser definida como a saída do estado de repouso do embrião e a retomada da atividade metabólica, sendo também o desenvolvimento do embrião e a emergência da plântula até tornarse independente das reservas da semente (FERREIRA; BORGHETTI, 2004; CARVALHO; NAKAGAWA, 2012). Externamente é marcada pelo rompimento da testa e a extrusão da plântula ou raiz primária (FENNER; THOMPSON, 2005).

Existem diversos fatores que influenciam no processo de germinação, podendo ser classificados como internos (intrínsecos, como longevidade e viabilidade) e externos, relacionados às condições ambientais, como umidade, temperatura, luz e oxigênio. A temperatura constitui um dos principais fatores que influenciam a semente, afetando a germinação total e a velocidade de germinação, pois tende a influenciar a velocidade de absorção de água e as reações bioquímicas determinantes no processo germinativo (FERREIRA; BORGHETTI, 2004; CARVALHO; NAKAGAWA, 2012).

Cada espécie apresenta uma temperatura mínima, máxima e ótima para a germinação. A temperatura é chamada de ótima quando ocorre o máximo de germinação no menor tempo. Acima e abaixo dos limites máximo e mínimo, respectivamente, pode ocorrer a morte dos embriões. A faixa de 20 a $30{ }^{\circ} \mathrm{C}$ mostra-se adequada para a germinação de grande número de espécies subtropicais e tropicais (LARCHER, 2003; FERREIRA; BORGHETTI, 2004; BRANCALION et al., 2010), que inclui as espécies do Pantanal.

Com relação às sementes de Cedrela fissilis coletadas em área do Pantanal, não existem estudos disponíveis na literatura sobre germinação de sementes, de modo que o objetivo deste trabalho foi avaliar o efeito de diferentes temperaturas na germinação de sementes e crescimento inicial de plântulas de cedro-rosa.

\section{MATERIAL E MÉTODOS}

Os frutos de Cedrela fissilis foram coletados na época da dispersão (julho-agosto/10), em áreas do Pantanal do Negro, município de Rio Negro, Mato Grosso do Sul, Brasil (19²9'12,2” a 19³0'49,8” sul e $55^{\circ} 35^{\prime} 28,5^{\prime \prime}$ a $55^{\circ} 42^{\prime} 37,9^{\prime \prime}$ oeste). A coleta foi realizada com o auxílio de tesoura de poda alta, em 16 matrizes localizadas em área de mata, considerando-se o porte, o vigor e a sanidade das árvores. Os frutos foram acondicionados em sacos plásticos e transportados para o Laboratório de Pesquisa em Sistemas Ambientais e Biodiversidade, Universidade Anhanguera-Uniderp, Campo Grande, MS, onde as sementes foram retiradas dos frutos, após sua abertura natural. Foi quantificado o teor de água nas sementes utilizando método de estufa a $105 \pm 3{ }^{\circ} \mathrm{C}$ por 24 horas, segundo metodologia descrita nas Regras para Análise de Sementes (BRASIL, 2009).

As sementes foram, inicialmente, imersas em solução de hipoclorito de sódio a $2 \%$ (v/v) por 2 minutos e, na sequência, lavadas em água corrente por 1 minuto, para desinfecção superficial. Para cada tratamento, foram utilizadas 200 sementes sem alas, divididas em quatro repetições de 50 unidades, acondicionadas em caixas plásticas transparentes $(11 \times 11 \times 3,5 \mathrm{~cm})$, sobre duas folhas de papel germitest previamente umedecidas com o fungicida Rovral a $1 \%$ com volume da solução equivalente a 2,5 vezes a massa seca do substrato, e colocadas em germinador, em presença de luz branca, com fotoperíodo de 12 horas, nas temperaturas constantes de $20,25,30$ e $35^{\circ} \mathrm{C}$ e alternadas de $20-30$ e $25-35^{\circ} \mathrm{C}$. 
O acompanhamento foi diário, durante o período de três semanas, procedendo-se à adição de água destilada no substrato quando necessário. A avaliação foi feita no último dia do experimento, considerando-se germinadas as sementes que originaram plântulas normais, com emissão de raiz primária e parte aérea.

As sementes não germinadas foram abertas com a utilização de bisturi e avaliadas quanto à integridade de suas estruturas, através de observação em estereomicroscópio.

Após a contagem final ( $18^{\circ}$ dias após a instalação do teste), todas as plântulas normais foram medidas (raiz primária e da parte aérea), com auxílio de uma régua graduada em centímetros. Em seguida, colocadas em sacos de papel enumerados, levados à estufa regulada a $60{ }^{\circ} \mathrm{C}$ até atingir peso constante (48 horas) e pesadas em balança analítica com precisão de 0,001 gramas.

O delineamento experimental foi o inteiramente casualizado. Seguindo procedimentos de Ferreira e Borghetti (2004), foram avaliados a percentagem de germinação e o índice velocidade de germinação (IVG), com o tempo médio de germinação (TMG) calculado de acordo com Maguire (1962) e os dados de percentagem de germinação transformados em arco seno $(\mathrm{x} / 100)^{0,5}$, sendo apresentados, na tabela, dados originais (não transformados), para melhor entendimento, com dados submetidos à análise de variância e comparação de médias pelo teste de Tukey (5\%). O valor da temperatura ideal, utilizando os valores das temperaturas constantes, foi obtido através de uma adaptação da fórmula de Bhaskara.

\section{RESULTADOS E DISCUSSÃO}

Em relação ao teor de água, as sementes apresentaram o valor de 50,5\%, semelhante ao encontrado por Corvello et al. (1999), entre 50 e $60 \%$. Esse teor, segundo os autores, é quando o fruto encontra-se parcialmente verde, podendo apresentar maior suscetibilidade a danos. Entretanto, os mesmos autores colocam que a melhor fase para a colheita de sementes de cedro com alta qualidade é aquela na qual é baixo o teor de água nas sementes, o que ocorre na $32^{\mathrm{a}}$ semana após a antese, quando as sementes apresentam teor de água aproximado de $22 \%$, com os frutos iniciando a deiscência. Esses resultados são distintos dos encontrados neste trabalho, em que sementes com alto teor de água apresentaram alta qualidade germinativa. Já Chinatto et al. (2011) citaram 13,2\% de umidade, abaixo do encontrado neste trabalho.

De acordo com Popinigis (1985), a semente adquire maior qualidade na maturidade quando ainda contém teores elevados de água, afirmação que corrobora os resultados encontrados por este trabalho.

A germinação das sementes de Cedrela fissilis (Figura 1) iniciou-se no $2^{\circ}$ dia após a instalação do experimento, para as temperaturas de 25,30 e $25-35^{\circ} \mathrm{C}$, estendendo-se até o $14^{\circ}, 13^{\circ}$ e $16^{\circ}$ dia após o início da germinação, respectivamente. Nas temperaturas de 20,35 e $20-30{ }^{\circ} \mathrm{C}$, o início da germinação ocorreu no $3^{\circ}$ dia, estendendo-se até o $16^{\circ}, 9^{\circ}$ e $16^{\circ}$ dia, respectivamente. Após esse período, o processo germinativo não teve continuidade, com as sementes não germinadas, após avaliação de suas estruturas, sendo consideradas mortas, com cotilédones apresentando aparência deteriorada (coloração enegrecida). De acordo com Brasil (2009), a contagem final de sementes desse gênero poderia ser feita no $28^{\circ}$ dia. Os dados obtidos para sementes coletadas no Pantanal indicam que, no máximo, o $20^{\circ}$ dia seria adequado.

As curvas de germinação, para a maioria das temperaturas testadas, apresentaram uma distribuição temporal, com um padrão normal ou gaussiano, de acordo com Borguetti e Ferreira (2004).

Em trabalhos com a espécie, Cherobini et al. (2008) iniciaram a contagem de sementes germinadas entre o $7^{\circ}$ e $14^{\circ}$ dias em laboratório, utilizando também o substrato papel e temperatura de $25^{\circ} \mathrm{C}$. Já em experimentos realizados por Lorenzi (2008) em substrato argiloso, a germinação ocorreu entre 12-18 dias, enquanto que Meneghello e Mattei (2004) observaram a germinação 22-28 dias após a semeadura.

A origem das sementes pode indicar que a espécie, quando coletada em áreas do Pantanal, possui germinação mais rápida, pois, segundo Carvalho e Nakagawa (2012), a origem da semente pode ter grande influência sobre seu comportamento durante a germinação.

Cherobini et al. (2008) avaliaram a qualidade de sementes de cedro coletadas na região Sul e verificaram que existem diferenças nos níveis de vigor entre as procedências, com $89 \%$ de germinação das sementes provenientes do Rio Grande do Sul, 79\% de Santa Catarina e 16\% do estado do Paraná. Já Santos et al. (2009) encontraram 66,2\% de germinação, com sementes coletadas na Paraíba e geminadas em casa de vegetação, também indicando diferenças de vigor, na dependência da origem. 


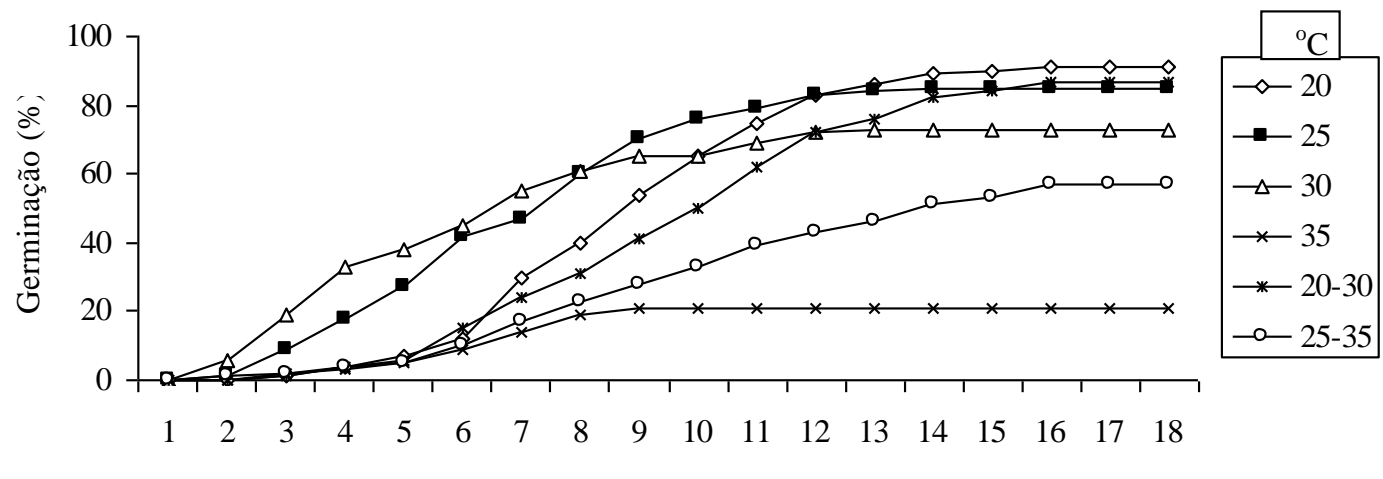

Dias

Figura 1. Germinação de sementes de Cedrela fissilis (dados acumulados) em quatro temperaturas constantes e duas temperaturas alternadas, em germinador.

Figure 1. Germination of Cedrela fissilis seeds (accumulated data) at four constant temperatures and two alternating temperatures in a germination chamber.

A maior percentagem de germinação, entre as temperaturas constantes, foi observada entre as temperaturas de 20 e $25^{\circ} \mathrm{C}\left(22,7^{\circ} \mathrm{C}\right)$, em que ocorreu o ponto máximo de germinação. À medida que a temperatura aumenta, a germinação é afetada negativamente, como pode ser observado na temperatura de $35^{\circ} \mathrm{C}$ (Figura 2).

Levando-se em consideração que os frutos de Cedrela fissilis são secos e suas sementes, aladas (anemocóricas), com dispersão geralmente ocorrendo entre os meses de julho e agosto, considerados os mais secos do ano na região e também período de inverno, de menores temperaturas, o ponto máximo de germinação encontrado neste trabalho é justificado pela correlação entre esses fatores.

Comparando-se as melhores temperaturas constantes com as alternadas (Figura 2), observa-se que a temperatura de $20-30{ }^{\circ} \mathrm{C}$ também é considerada adequada para a germinação das sementes da espécie, o que vem de encontro com a recomendação de Brasil (2009), em que a temperatura alternada de $20-30^{\circ} \mathrm{C}$ é a indicada. Já $25-35^{\circ} \mathrm{C}$, com menor germinabilidade, demonstra que mesmo em períodos de $12 \mathrm{~h}$ a temperatura de $35^{\circ} \mathrm{C}$ não é adequada.

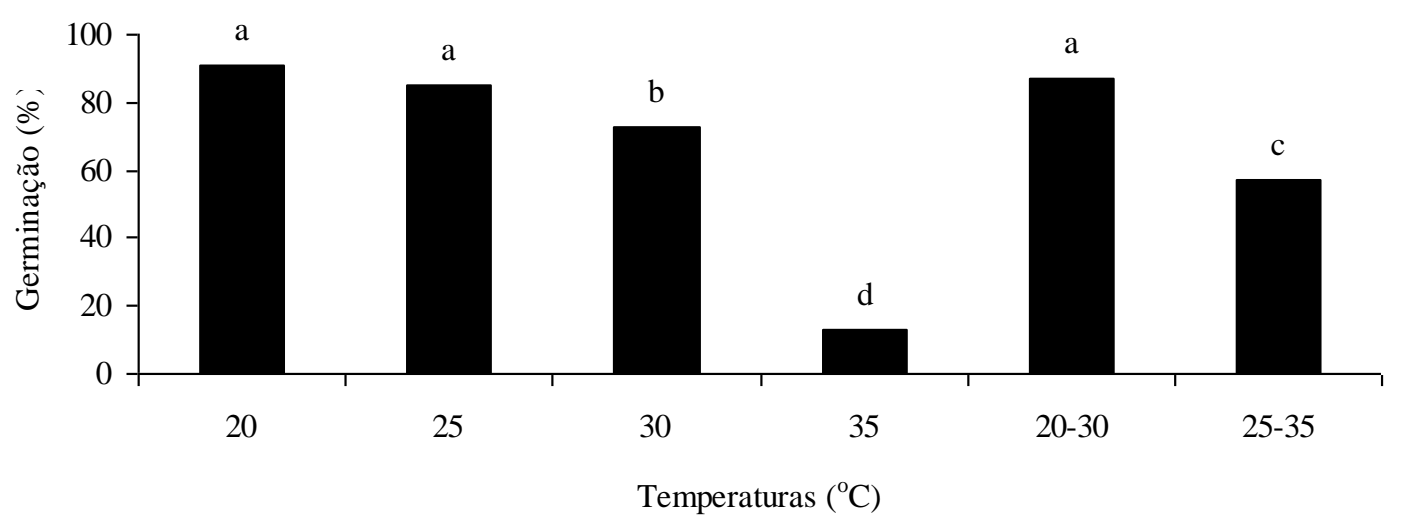

Figura 2. Germinação de sementes de Cedrela fissilis em duas temperaturas constantes e duas temperaturas alternadas, em germinador. As médias seguidas da mesma letra, não diferem entre si pelo teste de Tukey em 5\% de probabilidade.

Figure 2. Germination among Cedrela fissilis seeds cultivated at two constant temperatures and two alternating temperatures in a germination chamber. Average lengths followed by the same letter were not significantly different when subjected to Tukey's test, $5 \%$ probability. 
De acordo com Baskin e Baskin (2001), temperaturas inferiores ou superiores à ótima tendem a reduzir a velocidade do processo germinativo, expondo as sementes por maior período a fatores adversos, o que pode levar à redução no total de germinação, o que ocorreu na temperatura de $35^{\circ} \mathrm{C}$, inadequada para a espécie, nas condições testadas. Marcos Filho (2005) e Bradford e Nonogaki (2007) justificam esta menor germinação devido ao fato de temperaturas elevadas causarem danos às sementes de determinadas espécies, levando, por exemplo, a alterações enzimáticas, reduzindo a quantidade de aminoácidos livres e modificando a velocidade de reações metabólicas.

Cassaro-Silva (2001) também explica que, em temperaturas muito elevadas, em relação àquelas que a espécie tolera, a energia contida nas células ou sistemas de membranas celulares da semente pode ficar cada vez menos favorável ao crescimento do embrião, até atingir a temperatura máxima em que toda a energia é dissipada, ocorrendo nesse ponto processos como a desnaturação de proteínas, limitando a germinação, o que foi observado para a espécie.

Cherobini et al. (2008), avaliando sementes de Cedrela fissilis coletadas no RS e SC, utilizando apenas a temperatura de $25{ }^{\circ} \mathrm{C}$, obtiveram valores semelhantes aos do presente estudo (89\% e $79 \%$ ). Também Corvello et al. (1999), utilizando somente a temperatura de $25^{\circ} \mathrm{C}$ em estudos de maturação fisiológica do cedro, encontraram valores também aproximados (entre 86 e 93\%), resultado similar ao de Chinatto et al. (2011), com 83 e $87 \%$, melhores valores, para substrato areia e vermiculita, embora o substrato papel (30\%) tenha apresentado resultados inferiores aos encontrados neste trabalho.

Já Santos-Júnior et al. (2004), estudando a sobrevivência de espécies florestais nativas em sistema de semeadura direta em três ambientes diferentes em Lavras, Minas Gerais, constataram que as sementes do cedro demoraram mais a germinar no ambiente com sombreamento, o que não seria esperado, considerando o estágio sucessional da espécie. Os autores relacionaram o fato à menor temperatura encontrada no ambiente sombreado (cerca de $3{ }^{\circ} \mathrm{C}$ a menos que o ambiente a pleno sol). Porém, como as metodologias foram diferentes, não é possível afirmar que sementes daquela região germinaram em menor proporção.

Andrade e Pereira (1994), estudando o efeito da temperatura e substrato em outra espécie do mesmo gênero, Cedrela odorata L., encontraram as melhores taxas nas temperaturas de $25{ }^{\circ} \mathrm{C}(77 \%)$ e $30{ }^{\circ} \mathrm{C}(67 \%)$. Já Passos et al. (2008), com a mesma espécie, afirmaram que tanto as temperaturas constantes de 25 e $30{ }^{\circ} \mathrm{C}$ (86 e $80 \%$, respectivamente) como a alternada de $20-30{ }^{\circ} \mathrm{C}$ (90\%) são as melhores condições para a germinação das sementes, resultados semelhantes aos encontrados por este trabalho, diferindo apenas na temperatura constante de $30^{\circ} \mathrm{C}$.

Temperaturas alternadas podem favorecer a germinação de algumas espécies secundárias e pioneiras, de sementes pequenas, pois simulam as flutuações de temperaturas que ocorrem próximo ao solo, pois, segundo Baskin e Baskin (2001), apresentam mecanismos enzimáticos que funcionam em diferentes temperaturas e essa resposta, provavelmente corresponde a adaptações ecológicas da espécie ao ambiente, o que pode ser observado em $20-30{ }^{\circ} \mathrm{C}$.

Algumas espécies, como Amburana cearensis (Allemão) A. C. Smith., com sementes germinando em vermiculita em temperaturas constantes $\left(25,30\right.$ e $\left.35{ }^{\circ} \mathrm{C}\right)$ ou alternada $\left(20-30{ }^{\circ} \mathrm{C}\right)$ (GUEDES et al., 2010), ou Aspidosperma tomentosum Mart., em papel-filtro, nas temperaturas de 20, 25 e 25-35 ${ }^{\circ} \mathrm{C}$ (OLIVEIRA et al., 2011), demonstraram alta percentagem de germinação, resultados parcialmente similares aos encontrados por este trabalho, demonstrando diferentes adaptações das espécies.

Levando-se em consideração o vigor de germinação, avaliado indiretamente pelo IVG e TMG, a melhor condição de temperatura foi de $25{ }^{\circ} \mathrm{C}$, pois, além da melhor taxa de germinação, também apresentou a maior velocidade $(8,2)$ e o segundo menor tempo de germinação $(7,5$ dias), enquanto a temperatura de $20^{\circ} \mathrm{C}$ diminui o vigor, aumentando o tempo de germinação. As temperaturas alternadas também causaram uma diminuição no vigor de germinação, demonstrando que as mesmas não deveriam ser utilizadas para sementes coletadas na região do Pantanal (Tabela 1).

A temperatura de $30{ }^{\circ} \mathrm{C}$ apresentou IVG estatisticamente significativo $(8,2)$, igual ao obtido na temperatura de $25{ }^{\circ} \mathrm{C}$, e também o melhor TMG, porém a taxa germinativa, $73 \%$, foi inferior aos resultados obtidos para 20 e $25{ }^{\circ} \mathrm{C}$, demonstrando que essa temperatura mais elevada propicia maior vigor, porém afeta negativamente a germinação, indicando que nas condições testadas, temperaturas elevadas são inadequadas para a espécie.

$\mathrm{O}$ maior tempo para germinação, observado no TMG das temperaturas de 20 e $25{ }^{\circ} \mathrm{C}$, é decorrente, segundo Cassaro-Silva (2001), da grande dependência entre a velocidade de germinação e a temperatura, sendo que, quanto menor a temperatura, maior o tempo necessário para que as sementes germinem, embora a percentagem final de germinação possa ser alta, como o observado neste trabalho. 
Tabela 1. Índice de velocidade de germinação (IVG) e tempo médio de germinação (TMG) de sementes de Cedrela fissilis submetidos a diferentes temperaturas.

Table 1. Speed germination index (IVG) and mean germination time (TMG) of Cedrela fissilis seeds submitted to different temperatures.

\begin{tabular}{ccc}
\hline Temperatura $\left({ }^{\circ} \mathbf{C}\right)$ & IVG & TMG (dias) \\
\hline 20 & $6,1 \mathrm{~b}$ & $9 \mathrm{c}$ \\
25 & $8,2 \mathrm{a}$ & $7,5 \mathrm{~b}$ \\
30 & $8,2 \mathrm{a}$ & $5,8 \mathrm{a}$ \\
35 & $0,9 \mathrm{e}$ & $6,5 \mathrm{a}$ \\
$20-30$ & $4 \mathrm{c}$ & $9 \mathrm{c}$ \\
$25-35$ & $5 \mathrm{c}$ & $10,5 \mathrm{~d}$ \\
\hline
\end{tabular}

Médias seguidas pela mesma letra na coluna não diferem estatisticamente entre si, pelo teste de Tukey $(\mathrm{p}>0,05)$.

Avaliando-se o trabalho de Figliolia et al. (2006), os valores de IVG encontrados, com índices de 1,37 para a temperatura de $25{ }^{\circ} \mathrm{C}, 1,48$ na de $30{ }^{\circ} \mathrm{C}$ e 1,27 na temperatura constante de $20-30{ }^{\circ} \mathrm{C}$, são diferentes dos obtidos por esta pesquisa. Santos-Júnior et al. (2004) também encontraram pequeno vigor, com IVG de 2,16, em temperatura ambiente. Cherobini et al. (2008), utilizando somente a temperatura de $25^{\circ} \mathrm{C}$, encontraram IVG de 1,7. Chinatto et al. (2011), também na mesma temperatura, citaram o melhor IVG, em areia, sendo abaixo de 3,5. Já Santos-Júnior et al. (2004), em temperatura de $25^{\circ} \mathrm{C}$, citaram IVG de 6,8 , seguido da temperatura de $30^{\circ} \mathrm{C}$, com 7,3 , valores similares aos encontrados neste trabalho.

Os maiores valores de IVG encontrados para esta pesquisa, nas temperaturas de 25 e $30{ }^{\circ} \mathrm{C}$, podem estar associados à qualidade fisiológica das sementes e sua origem. Também o substrato pode ter interferido, pois os trabalhos citados acima usaram substratos diferentes do presente estudo, como vermiculita e areia, entre outros.

Outro parâmetro avaliado foi a produção de matéria seca e comprimento das plântulas (Figura 3). A temperatura constante de $25{ }^{\circ} \mathrm{C}$, levando-se em consideração os dois parâmetros avaliados, apresentou o melhor desenvolvimento de plântulas, maiores e mais pesadas.

As temperaturas de 20 e $20-30^{\circ} \mathrm{C}$ também propiciaram bom crescimento, mas com acúmulo de massa seca menor. A temperatura de $30^{\circ} \mathrm{C}$ também produziu plântulas de maior massa seca, porém com menor tamanho (Figura 3).

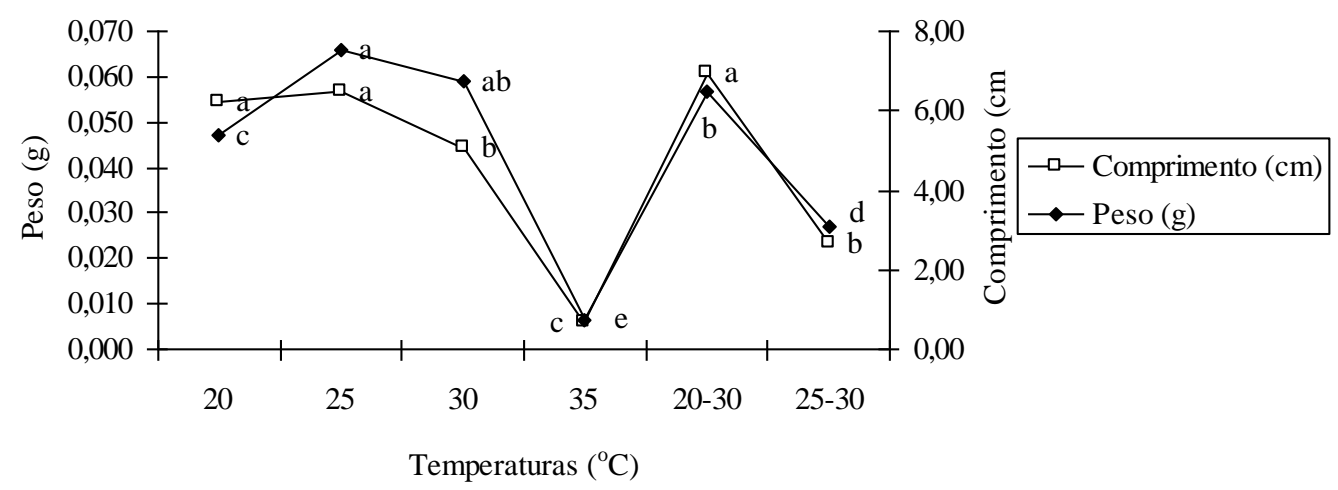

Figura 3. Tamanho médio ( $\mathrm{cm}$ ) e peso ( $\mathrm{g}$ ) de plântulas da espécie Cedrela fissilis submetidas a diferentes temperaturas. As médias seguidas da mesma letra não diferem entre si pelo teste de Tukey em $5 \%$ de probabilidade.

Figure 3. Average length $(\mathrm{cm})$ and weight $(\mathrm{g})$ of seedlings $(\mathrm{mm})$ of Cedrela fissilis, cultivated at different temperatures. Average lengths followed by the same letter were not significantly different when subjected to Tukey's test, $5 \%$ probability.

Oliveira et al. (2013), com sementes de Diptychandra aurantiaca (Mart.) Tul. crescendo em substrato papel, demonstraram que as temperaturas de 25 e $30{ }^{\circ} \mathrm{C}$ foram as mais adequadas para o 
crescimento da raiz primária, resultado parcialmente similar ao encontrado neste trabalho, com sementes de Cedrela fissilis.

O crescimento da plântula é geralmente viável sob uma ampla faixa de temperatura, variando entre 2 e $5{ }^{\circ} \mathrm{C}$ para espécies lenhosas de zona temperada e acima de $10^{\circ} \mathrm{C}$ para vegetais de regiões tropicais (LARCHER, 2003). A temperatura ótima para a divisão celular é de aproximadamente $30^{\circ} \mathrm{C}$ para a maioria das espécies, portanto próxima da temperatura ótima para o crescimento (FERREIRA; BORGHETTI, 2004), embora este trabalho tenha encontrado a temperatura de $25{ }^{\circ} \mathrm{C}$ como a mais adequada para a espécie estudada.

A somatória de todos os parâmetros avaliados demonstra que a temperatura de $25{ }^{\circ} \mathrm{C}$ pode ser a mais indicada, pois as sementes apresentaram maior percentagem de germinação $(85 \%)$, IVG $(8,2)$, segundo maior TMG (7,5 dias), maior comprimento da raiz $(4,1 \mathrm{~cm})$ e segunda maior altura de parte aérea $(4,8 \mathrm{~cm})$, além de maior peso seco e parte aérea mais desenvolvida, resultados similares aos citados por Figliolia et al. (2006).

\section{CONCLUSÃO}

- Apesar de as Regras para Análise de Sementes (BRASIL, 2009) recomendarem a temperatura alternada de $20-30{ }^{\circ} \mathrm{C}$ para a condução do teste de germinação com sementes do gênero Cedrela, os resultados obtidos neste trabalho demonstram que as sementes de Cedrela fissilis coletadas na região do Pantanal também alcançaram maiores taxas de germinação nas temperaturas de 20 e $25^{\circ} \mathrm{C}$, além da temperatura alternada de $20-30{ }^{\circ} \mathrm{C}$. Porém o maior vigor foi obtido nas temperaturas de 25 e $30{ }^{\circ} \mathrm{C}$, além de a temperatura de $25^{\circ} \mathrm{C}$ produzir plântulas mais vigorosas, o que indica sua melhor adequação para a espécie estudada.

\section{AGRADECIMENTOS}

À Universidade Anhanguera-Uniderp, pelo financiamento do projeto GIP (Grupo Interdisciplinar de Pesquisa), e à Capes e CNPq, pelas bolsas concedidas.

\section{REFERÊNCIAS}

ANDRADE, A. C. S.; PEREIRA, T. S. Efeito do substrato e da temperatura na germinação e no vigor de sementes de cedro - Cedrela odorata L. (Meliaceae). Revista Brasileira de Sementes, v. 16, n. 1, p. 34 40, 1994.

BASKIN, C. C.; BASKIN, J. M. Seeds: ecology, biogeography, and evolution of dormancy and germination. San Diego: Academic Press, 2001. 666 p.

BORGHETTI, F.; FERREIRA, A. G. Interpretação de resultados de germinação. In: FERREIRA, A. G.; BORGHETTI, F. (Eds.). Germinação: do básico ao aplicado. Porto Alegre: Artmed, 2004. p. 209 - 222.

BRADFORD, K. J.; NONOGAKI, H. Seed development, dormancy and germination. Oxford: Blackwell Pub, 2007. 392 p.

BRANCALION, P. H. S.; NOVEMBRE, A. D. L. C.; RODRIGUES, R. R. Temperatura ótima de germinação de sementes de espécies arbóreas brasileiras. Revista Brasileira de Sementes, Londrina, v. 32, n. 4, p. 15 - 21, 2010.

BRASIL. Ministério da Agricultura, Pecuária e Abastecimento. Regras para análise de sementes. Brasília: Secretaria de Defesa Agropecuária. MAPA/ACS, 2009. 395 p.

CASSARO-SILVA, M. Efeito da temperatura na germinação de sementes de manduirana (Senna macranthera (Collad.) Irwin et Barn. - Caesalpiniaceae). Revista Brasileira de Sementes, Londrina, v. 23, n. 1, p. 92 - 99, 2001.

CARVALHO, P. E. R. Espécies florestais brasileiras: recomendações silviculturais, potencialidades e uso da madeira. Colombo: EMBRAPA-CNPF/SPI, 1994. 639 p. 
CARVALHO, N. M.; NAKAGAWA, J. Sementes: ciência, tecnologia e produção. 5. ed. Jaboticabal: FUNEP, 2012. $590 \mathrm{p}$.

CHEROBINI, E. A. I.; MUNIZ, M. F. B.; BLUME, E. Avaliação da qualidade de sementes e mudas de cedro. Ciência Florestal, Santa Maria, v. 18, n. 1, p. 65 - 73, 2008.

CHINATTO, E.; BALDISSERA, F. G.; AVILA, A. L. Caracterização e avaliação da germinação de sementes de cedro (Cedrela fissilis Vell.) submetidas a diferentes substratos. Unoesc \& Ciência ACET, Joaçaba, v. 2, n. 2, p. 129 - 138, 2011.

CORVELlO, W. B. V.; VILLELA, F. A.; NEDEL, J. L.; PESKE, S. T. Época de colheita e armazenamento de sementes de cedro (Cedrela fissilis Vell.). Revista Brasileira de Sementes, v. 21, p. $23-27,1999$.

FENNER, M.; THOMPSON, K. The ecology of seeds. Cambridge: Cambridge University Press, 2005. $250 \mathrm{p}$.

FERREIRA, A. G.; BORGHETTI, F. Germinação: do básico ao aplicado. Porto Alegre: Artmed, 2004. $323 \mathrm{p}$.

FIGLIOLIA, M. B.; AGUIAR, I. B.; SILVA, A. Germinação de sementes de Lafoensia glyptocarpa Koehne (mirindiba-rosa), Myroxylon peruiferum L. f. (cabreúva-vermelha) e Cedrela fissilis Vell. (cedrorosa). Revista do Instituto Florestal, São Paulo, v. 18, p. 49 - 58, 2006.

GUEDES, R. S.; ALVES, E. U.; GONÇALVES, E. P. Substratos e temperaturas para testes de germinação e vigor de sementes de Amburana cearensis (Allemão) A. C. Smith. Revista Árvore, Viçosa, v. 34, n. 1, p. 57 - 64, 2010.

LARCHER, W. Physiological plant ecology: ecophysiology and stress physiology of functional groups. Berlin: Springer, 2003. 533 p.

LORENZI, H. Árvores brasileiras: manual de identificação e cultivo de plantas arbóreas nativas do Brasil. 5 ed. Nova Odessa: Plantarum, v. 1, 2008. 384 p.

2002. $512 \mathrm{p}$.

Plantas medicinais no Brasil: nativas e exóticas cultivadas. Nova Odessa: Instituto Plantarum,

MAGUIRE, J. D. Speed of germination aid in selection and evaluation for seedling and vigor. Crop Science, Madison, v. 2, n. 2, p. 176 - 177, 1962.

MARCOS FILHO, J. Fisiologia de sementes de plantas cultivadas. Piracicaba: FEALQ, 2005. 495 p.

MENEGHELLO, G. E.; MATTEI, V. L. Semeadura direta de timbaúva (Enterolobium contortisiliquum), canafístula (Peltophorum dubium) e cedro (Cedrela fissilis) em campos abandonados. Ciência Florestal, Santa Maria, v. 14, n. 2, p. 21 - 27, 2004.

OLIVEIRA, A. K. M.; RIBEIRO, J. W. F.; PEREIRA, K. C. L.; SILVA, C. A. A. Germinação de sementes de Aspidosperma tomentosum Mart. (Apocynaceae) em diferentes temperaturas. Revista Brasileira de Biociências, Porto Alegre, v. 9, n. 3, p. 392 - 397, 2011.

OLIVEIRA, A. K. M.; RIBEIRO, J. W. F.; PEREIRA, K. C. L.; SILVA, C. A. A. Effects of temperature on the germination of Diptychandra aurantiaca (Fabaceae) seeds. Acta Scientiarum. Agronomy, Maringá, v. 35, n. 2, p. 203 - 208, 2013.

PASSOS, M. A. A.; SILVA, F. J. B. C.; SILVA, E. C. A.; PESSOA, M. M. L.; SANTOS, R. C. Luz, substrato e temperatura na germinação de sementes de cedro-vermelho. Pesquisa Agropecuária Brasileira, Brasília, v. 43, n. 2, p. 281 - 284, 2008.

POPINIGIS, F. Fisiologia da semente. Brasília: Agiplan, 1985. 289 p. 
SALOMÃO, A. N.; SILVA, J. C. S.; DAVIDE, A. C.; GONZALES, S.; TORRES, R. A. A.; WETZEL, M. M. V. S.; FIRETTI, F.; CALDAS, L. S. Germinação de sementes e produção de mudas de plantas do Cerrado. Brasília: Rede de Sementes do Cerrado, 2003. 96 p.

SANTOS-JÚNIOR, N. A.; BOTELHO S. A.; DAVIDE A. C. Estudo da germinação e sobrevivência de espécies arbóreas em sistema de semeadura direta, visando à recomposição de mata ciliar. Cerne, Lavras, v. 10, n. 1, p. 103 - 117, 2004.

SANTOS, S. S.; MOURA, M. F. de; GUEDES, R. S. Emergência e vigor de plântulas de Cedrela fissilis L. em função de diferentes posições de profundidades de semeadura. Revista Biotemas, Florianópolis, v. 22, n. 4, p. $45-52,2009$.

XAVIER, A.; SANTOS, G. A.; OLIVEIRA, M. L. Enraizamento de miniestaca caulinar e foliar na propagação vegetativa de cedro-rosa (Cedrela fissilis Vell.). Revista Árvore, Viçosa, v. 27, n. 3, p. 351 356, 2003. 
